NASA Technical Memorandum 85886

NASA-TM-8588619840008459

\title{
Techniques for Avoiding Discrimination Errors in the Dynamic Sampling of Condensable Vapors
}

Kenneth A. Lincoln

\section{FOR REFERENCE}

2xx

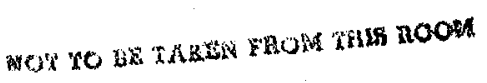

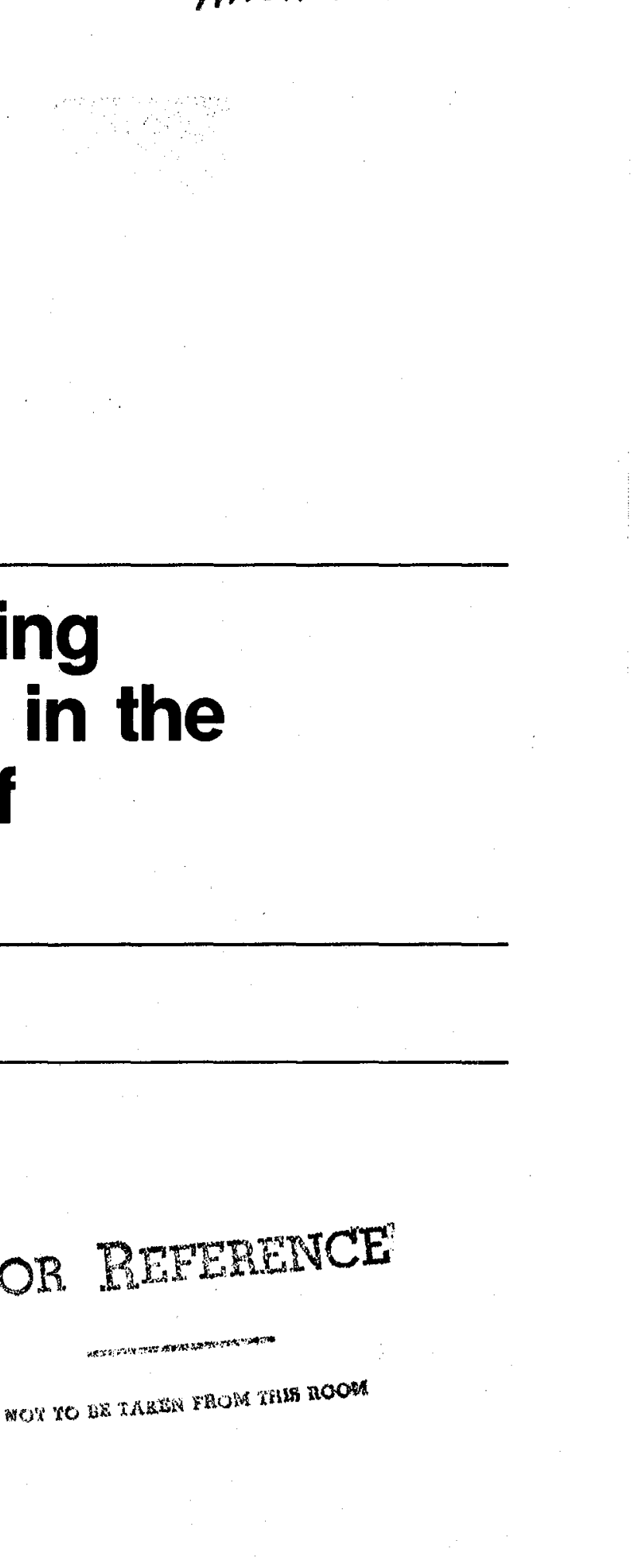

4.

$\because 86 \quad 1984$

LANGLEY RESEARS: N NTER

LIBRARY, NASA

HAMPTON, VIRGINIA 
NASA Technical Memorandum 85886

\section{Techniques for Avoiding Discrimination Errors in the Dynamic Sampling of Condensable Vapors}

Kenneth A. Lincoln, Ames Research Center, Moffett Field, California

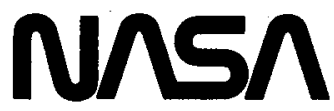

National Aeronautics and

Space Administration 



\title{
TECHNIQUES FOR AVOIDING DISCRIMINATION ERRORS IN THE DYNAMIC SAMPLING OF CONDENSABLE VAPORS
}

\author{
KENNETH A. LINCOLN \\ NASA Ames Research Center, Moffett Field, Calif. 94035 (U.S.A.)
}

\section{ABSTRACT}

In the mass spectrometric sampling of dynamic systems, measurements of the relative concentrations of condensable and noncondensable vapors can be significantly distorted if some subtle, but important, instrumental factors are overlooked. Even with in situ measurements, the condensables are readily lost to the container walls, and the noncondensables can persist within the vacuum chamber and yield a disproportionately high output signal. Where single pulses of vapor are sampled this source of error has been avoided by gating either the mass spectrometer "on" or the data acquisition instrumentation "on" only during the very brief time-window when the initial vapor cloud emanating directly from the vapor source passes through the ionizer. Instrumentation for these techniques is detailed and its effectiveness is demonstrated by comparing gated and nongated spectra obtained from the pulsed-laser vaporization of several materials.

\section{INTRODUCTION}

Inasmuch as most mass spectrometric dynamic sampling is done by dynamic instruments, it seems reasonable that the subject of dynamic sampling is appropriate for this symposium. But to avoid confusion, some definitions are appropos at the outset. In the absence of any other definition known to this author, it is assumed here that a dynamic mass spectrometer is one in which the mass dispersion is achieved by a time-variant means within the analyzer. Quite independent of this is the technique or process of dynamic sampling, which is the real-time measurement of gases whose composition is timevariant. In this paper some common problems are pointed out and caveats noted that are relevant to condensable vapors and unstable species that are involved in dynamic sampling, and some techniques for overcoming these problems are illustrated.

Figure 1 is a simplified schematic of a typical mass spectrometer system. Gases are generated or injected at the vapor source and they flow through the ionizer of the mass spectrometer and out through the vacuum pumps; electrical signals from the detector come out of the spectrometer on a wire(s) into some kind of recording device. The list of recording instruments included in the figure represents the most common ones, but is not necessarily complete. At the input end of the system is a list of vapor sources that represent common applications of mass spectrometry and are usually (but not always) associated with dynamic sampling processes. Furthermore, these sources are usually associated with temperatures higher than other parts of the instrument and this is where trouble can begin for the unsuspecting spectrometrist.

Some investigators have recognized these potential pitfalls in their work, and apparently others have not. For instance, Wells et al. (ref. 1) have pointed out that pyrolysis in an expansion chamber external to the ion source leads to problems of wall collisions causing losses of unstable intermediates

This paper was published in the International Journal of Mass Spectrometry and Ion Processes, 1984. 


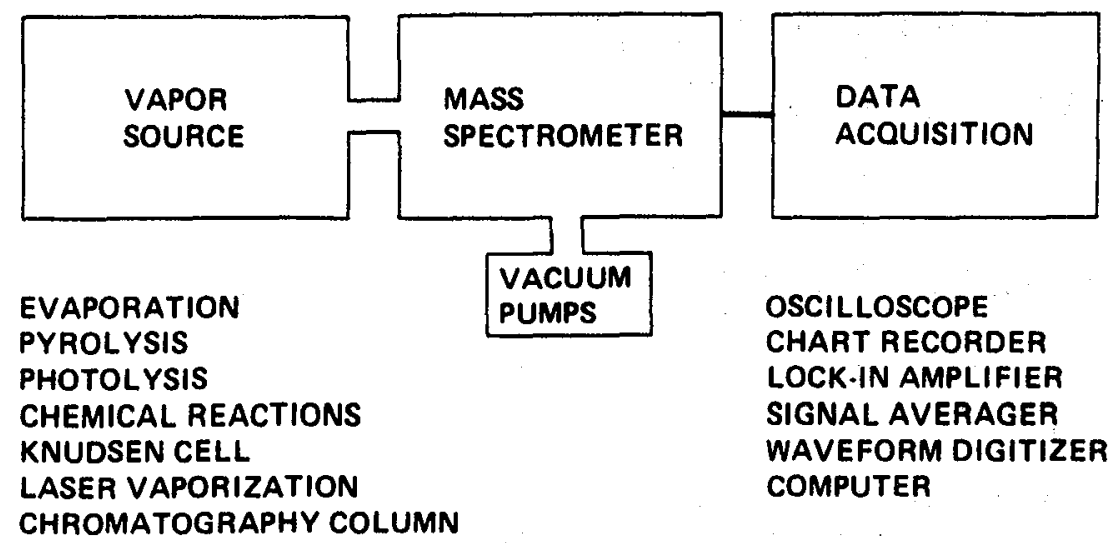

Fig. 1. Schematic of typical mass spectrometer system.

and adsorption of high-mass fragments plus gas-phase reactions that remove the highly reactive species. Furthermore, it is to be expected that accurate dynamic sampling by mass spectrometry can be degraded by such factors as (1) a long multicollision vapor path into the ionizer, (2) a large temperature differential between the vapor source and the ionizer which could cause loss of condensables, (3) a mixture of vapor species having a wide range of condensation temperatures, and (4) mixtures that contain transient, short-lived species. Solutions to the above lie along the following lines:

1. Shorten the vapor path to the ionizer. In many cases the vapor source is brought into proximity with the ionizer. But this may not be a complete cure, as we shall see later.

2. Provide a series of collimating slits with or without differential pumping. In the classic hightemperature work described in detail by Inghram and Drowart (ref. 2) a series of fixed slits was installed plus a "movable beam defining slit" to discriminate the Knudsen effusion beam from background, including the reflected species, etc.

3. Form the vapor flow into a molecular beam that is chopped in synchronism with the dataacquisition system in such a manner that the background is subtracted out. This technique of operating with molecular beam inlets has become increasingly popular (ref. 3). Pulsed-laser heating is a special case of this, and examples will be given later.

4. Employ cryogenic-cooled traps and baffles which limit the vapors entering the ionizer to a lineof-sight beam geometry that passes through the ionizer and is then condensed to avoid interference (ref. 1). However, all of the vapors must be condensed on the first pass, otherwise discrimination can result.

The work described here incorporates some of these methods, as well as some data acquisition techniques to minimize the discrimination errors described above.

\section{EXPERIMENTAL}

Figure 2 depicts the layout of the laser/mass spectrometer system which has undergone some modifications from that described earlier (ref. 4). It is designed so that vaporization of samples positioned in the high-vacuum chamber can be achieved by the pulsed $\mathrm{Nd:glass} \mathrm{laser} \mathrm{at} \mathrm{1.06} \mu \mathrm{m}$ or by the continuous $\mathrm{CO}_{2}$ laser at $10.6 \mu \mathrm{m}$ wavelength. The volume of the expansion high-vacuum chamber and mass spectrometer is 185 liters. A nude ion source has been attached to the CVC (Bendix) Model MA-2 time-of-flight mass spectrometer (TOFMS); this provides a very open structure which enhances 
rapid pump-out of gas pulses. The baffle does not completely isolate the two vacuum chambers, but serves to prevent contamination of the electrodes in the ion source and serves to collimate the vapors that have left the surface of the sample in a free-jet expansion (ref. 5). Thus, the laser-induced vapors follow a line-of-sight path (as shown in the expanded portion of Fig. 2) through the ionizing electron beam and out of the ionizer while sustaining minimal collisions with grids and support structures. The TOFMS is normally operated at a repetition rate to produce 40 spectra per millisecond. $\mathrm{A} \mathrm{He}-\mathrm{Ne}$ laser beam (not shown) is coaxial with either the pulsed or continuous laser beam and illuminates the target spot to facilitate alignment.

The most convenient means of recording spectra produced by the pulsed laser is by operating the TOFMS continuously at a fast repetition rate with the spectra displayed on an oscilloscope which is photographed by a camera whose flash-synchronized shutter fires the laser. An example of this type of recording is shown in Fig. 3 which shows a spectrum of vapors produced by a single shot of the pulsed laser on a solid material. Actually, it is an overlay of more than 1200 spectra which occurred during the 1/30-s shutter speed of the camera (repetition rate of the TOFMS was $40 \mathrm{kHz}$ ). Although they are of very significant amplitude in the photograph, the mass peaks at 12, 24, and 36 are extremely faint. This is because they represent the short-lived, condensable carbon species, the bright peaks are due to the fixed gases $\mathrm{H}_{2}, \mathrm{CH}_{4}, \mathrm{H}_{2} \mathrm{O}, \mathrm{C}_{2} \mathrm{H}_{2}$, and $\mathrm{CO}$. (The peak broadening is indicative of a

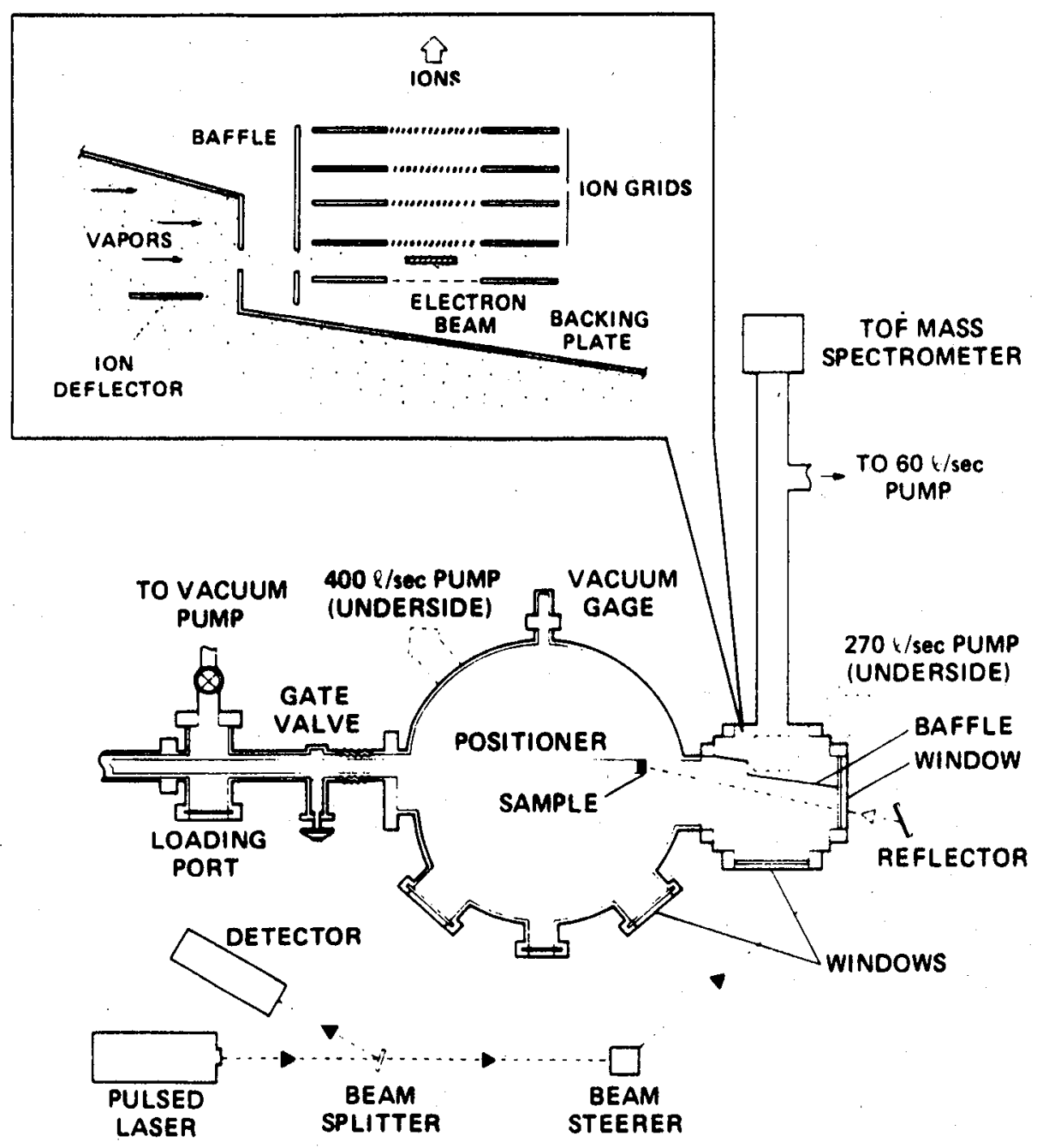

Fig. 2. Advanced laser/mass spectrometer system. 


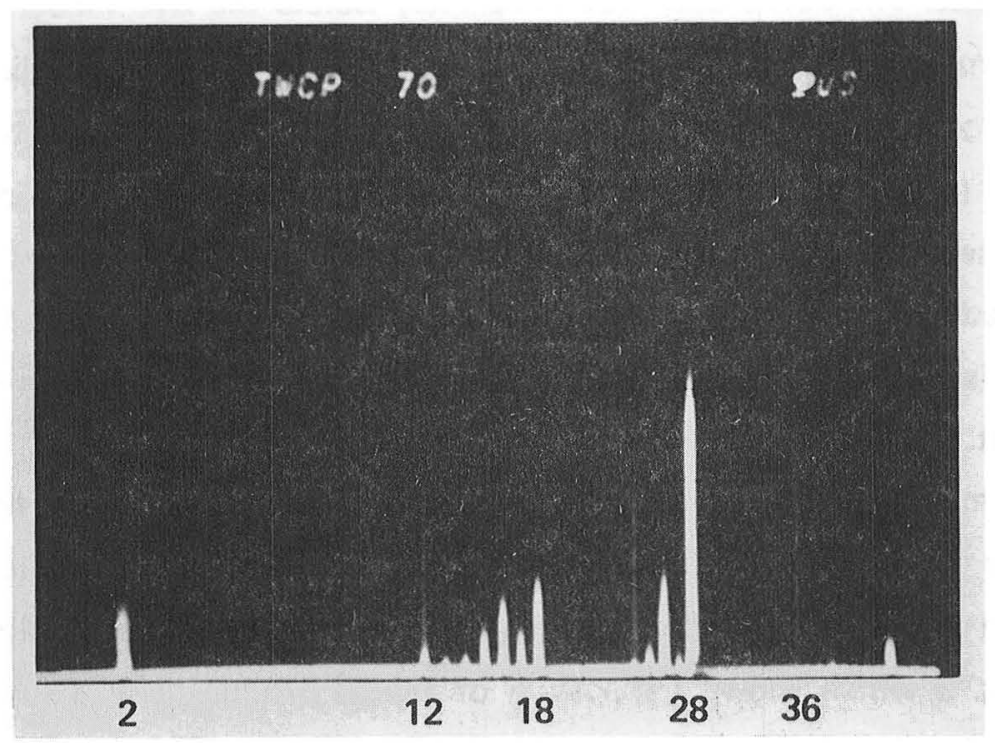

Fig. 3. Mass spectrum of vapor products from pulsed-laser heating of carbon phenolic composite.

pressure surge in the flight tube). This difference in brightness is explained by reference to Figure 4 , which shows the laser output and the total vapor pulse resulting from the same laser shot that produced the spectrum of Fig. 3. The approximately 1.0-ms pulse of the total mass current is generated as the vapor cloud from the target transits the ionizer; the tail which extends for tens of milliseconds or more results from the noncondensables reflecting off the walls and flooding the ion source housing whence they continue to produce spectra until they are pumped out. This is in contrast to the condensable or transient species which are eliminated upon collision with a wall. Thus, a discrimination is effected when the recording time of the output spectra is long compared with the time of the initial vapor cloud transiting the ionizer. The data displayed in Fig. 4 were acquired using the older TOFMS configuration which had a more closed ion-source housing than that depicted in Fig. 2, and a vapor path of approximately $50 \mathrm{~cm}$ from sample to ionizer. Figure 5 displays the vapor pulse produced from the configuration of Fig. 2 (vapor path of $11 \mathrm{~cm}$ ); the benefits of the improved collimation and the open (better pumped) ion source are evidenced by the reduced tail.

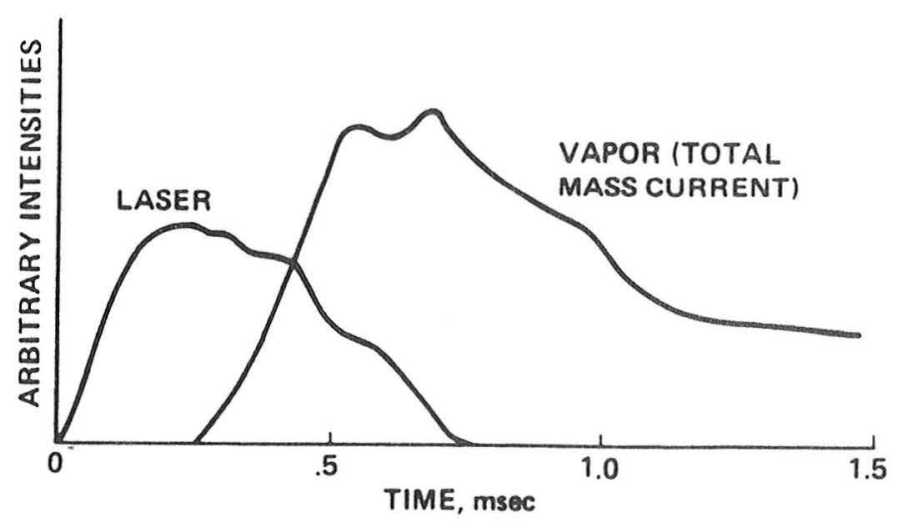

Fig. 4. Relationship between laser pulse and resulting vapor pulse from carbon phenolic composite. 


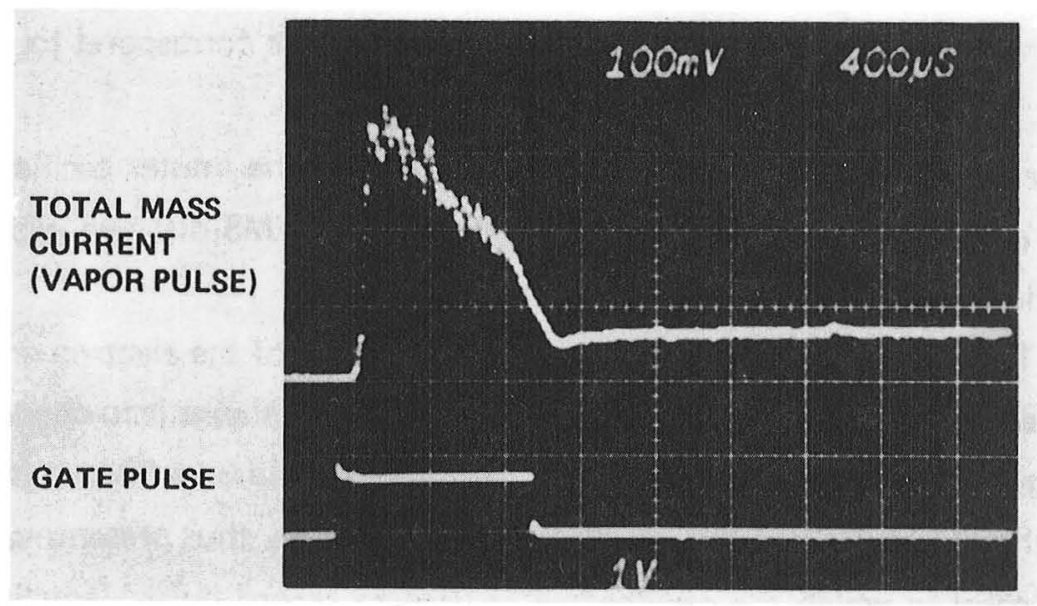

Fig. 5. Laser-induced vapor pulse from $W_{2} C$ and gating pulse to data acquisition. Vertical scale: upper $100 \mathrm{mV} \operatorname{div}^{-1}$; lower $1 \mathrm{~V} \operatorname{div}^{-1}$; time scale: $400 \mu \mathrm{siv}^{-1}$.

The remainder of this paper will be limited to a discussion of methods for further avoiding the above described discrimination by the technique of acquiring mass spectra only during the timewindow when the initial vapor cloud emanating directly from the vapor source transits the ionizer. This is achieved in several ways by employing the gate pulse, shown in Fig. 5, as an adjustable window which is delayed in time to coincide with the vapor pulse to be analyzed. In this case, the time-width was adjusted for $1 \mathrm{~ms}$ to include the whole vapor pulse, but it can be varied to permit sampling any portion thereof. Six methods are outlined below for obtaining time-window mass spectra from the instrumentation presented schematically in Fig. 6. In all cases, a pulse generator with a variable delay triggered by the laser is used to gate "on" either the mass spectrometer or the data acquisition instrumentation after a preselected time interval; the pulse amplitude requirements may vary depending on

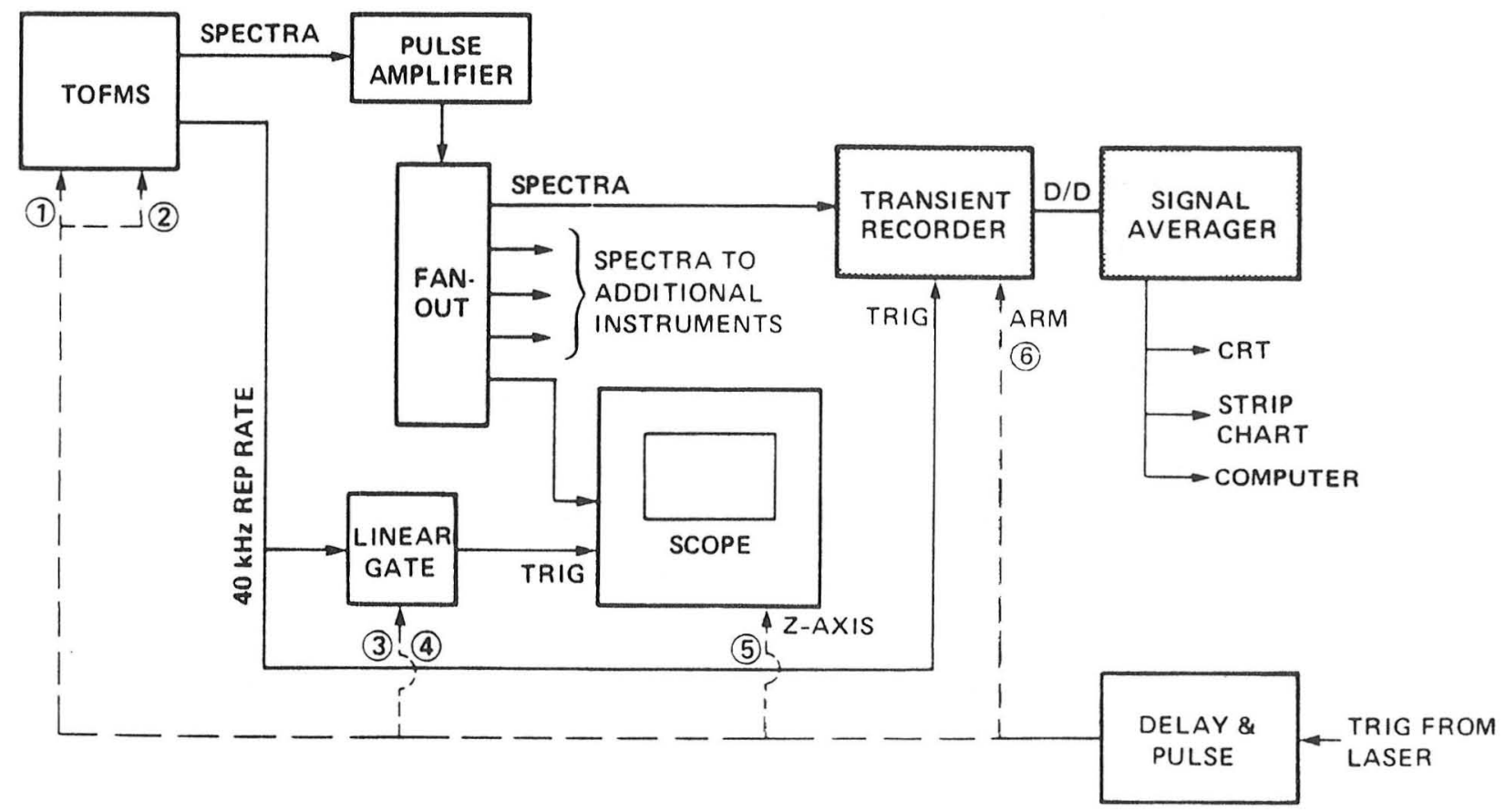

Fig. 6. Instrumentation for presenting gated mass spectra. 
which component in the system is controlled (the following numbers correspond to those circled in Fig. 6):

1. Master oscillator of TOFMS. In those instruments in which the master oscillator can be controlled by an external gate, it is a simple matter to operate the TOFMS disabled with no spectra or trigger outputs except during the brief interval of the gate pulse.

2. Electron beam. The TOFMS is operated normally except one of the electron grids (usually not the control grid) is biased to cut off until the gate pulse is applied and allows it to conduct.

3. Oscilloscope trigger. The trigger pulses to the scope are blocked by a linear gate (Ortec, Model LG105) except when the gate pulse is applied and allows them to pass, thus presenting the input spectra on the CRT. In all cases in which the oscilloscope is used to record pulsed-laser induced spectra, the camera is set at the lowest exposure time feasible and the flash-synchronized shutter fires the l-ser.

4. Oscilloscope trigger and raster. This is similar to the previous method except that an oscilloscope offset trace controller (CVC, Model MA-007) provides a preselected number of triggers to the scope after it has been activated by the gate pulse. This unit also provides vertical displacement to yield a raster presentation on the scope. Alternative electronics and a good description of rastering are given by Price and Vaudrey (ref. 6).

5. Oscilloscope z-axis. All systems are operating continuously, but the intensity control of the scope is set to blank the CRT. A negative gate pulse of sufficiently high amplitude is applied to the $z$-axis input to allow the scope to present spectra during the selected time window.

6. Waveform digitizer. The spectra are presented to the transient recorder (Biomation, Model 8100 ) which is triggered by the TOFMS (similar to the scope) so that specific mass peaks are always stored in the same location in the memory. However, the recorder is dormant until the gate pulse arms it allowing the next arriving trigger pulse from the TOFMS to initiate the storage of a spectrum in the memory; the captured spectrum then corresponds to a time that is slightly after the leading edge of the gate pulse. This method has the disadvantage that only one spectrum from the TOFMS can be captured per laser pulse. Nevertheless, this feature can be used to analyze vapor clouds as a function of time following the laser pulse, and it has been exploited effectively by Van Breeman et al. (ref. 7).

Figure 6 also shows a signal averager (Nicolet, Model 1170) connected to the output of the transient recorder with digital-to-digital data transfer. We have found this to be a very effective means of overcoming the inherently poor statistical fluctuations that occur among individual spectra in a TOFMS. By averaging a number of single spectra obtained after identical time delays from successive laser pulses on the same sample material, it is possible to obtain very reproducible results. Figure 7 is an example of a spectrum obtained by averaging one spectrum from each of 14 laser pulses irradiating the same spot on a tungsten carbide sample. This technique for acquiring TOFMS spectra via a signal averager has been described in greater detail previously (ref. 4), and currently we are also using it to obtain the spectra of calibration gases under constant-flow inlet conditions. This has proved to be very convenient, because 1000 spectra can be averaged in about $4 \mathrm{~s}$ and the resulting spectrum stored in digital form in the memory, from which it is transferred to a computer for subsequent calculations, etc.

Figure 8 is a display of two bar-graph spectra derived from photographs of the scope recording of TOFMS outputs resulting from pulsed-laser vaporization of cellulose. The gated spectrum was 


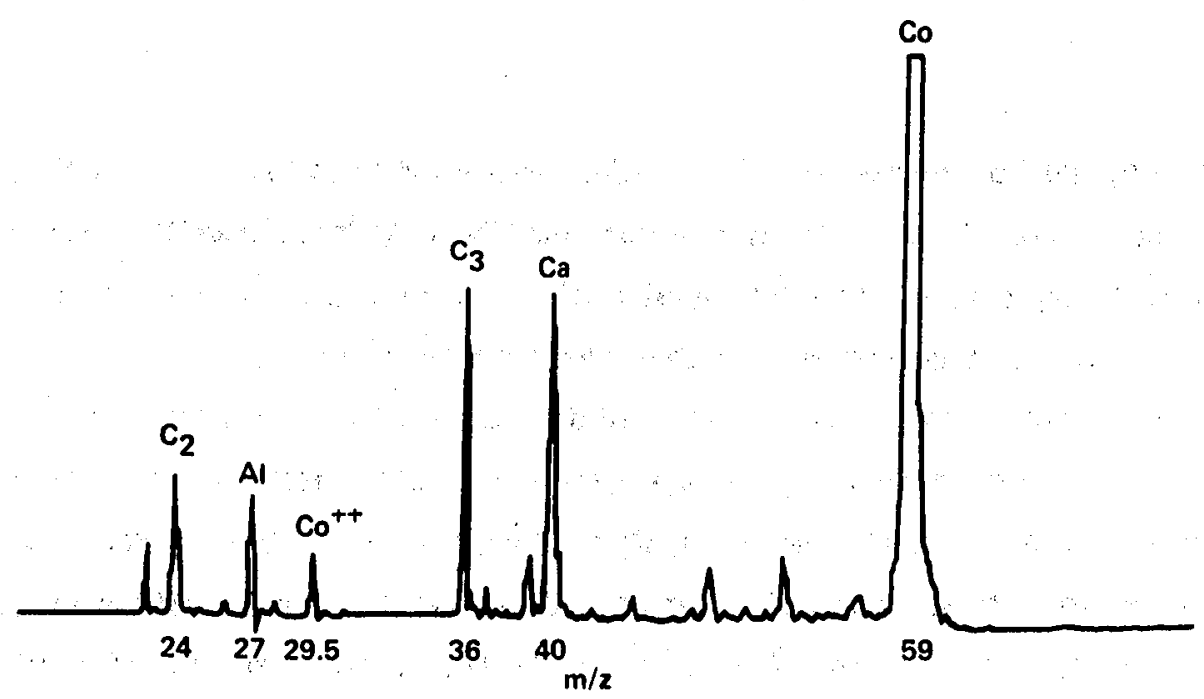

Fig. 7. Summed mass spectra of vapors from 14 laser pulses on WC (4\% Co).

PULSE PEAK APPROXIMATELY $7 \mathrm{~kW} / \mathrm{cm}^{2}$
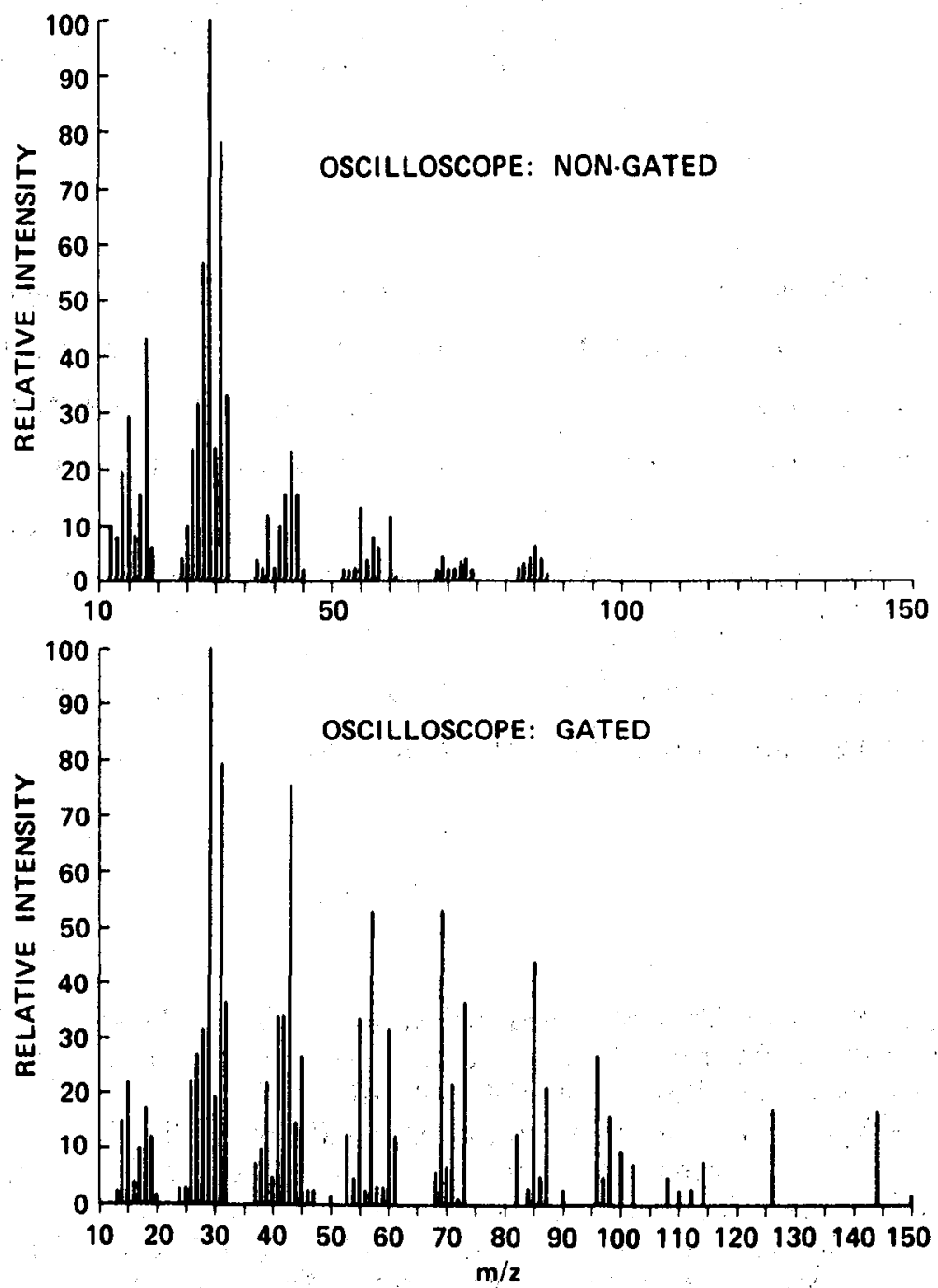

Fig. 8. Mass spectra from laser-vaporized alpha-cellulose. 
obtained using method one above wherein the master oscillator was enabled for a period of $1 \mathrm{~ms}$ by the gating pulse. Here it can be seen that the higher-molecular-weight components appear in the gated spectrum, but they escaped detection in the nongated spectrum which was a 1/30-s exposure from a continuously running spectrometer. In this case the high $\mathrm{m} / \mathrm{z}$ values are attributed to the alpha cellulose monomer, levoglucosan which is solid at room temperature and presumably condensed on the ion source walls at first encounter. Again, these particular data were acquired when the instrumentation was in the previous configuration with the longer vapor path of approximately $50 \mathrm{~cm}$. Comparison of these results with some unpublished work by this author performed several years previously, using the same cellulose material but with an earlier TOFMS model without benefit of the time-window (ref. 8), show some significant similarities: the present long-exposure spectra are quite similar to those obtained in the earlier work from samples flash-heated in a glass appendage on the ion-source housing, and the present "window" spectra are nearly identical with those from the earlier laser-heated material when the sample was about $5 \mathrm{~cm}$ from the ionizer; the latter show a much greater abundance of highmolecular-weight components. It can be concluded from this that close proximity to the ion source is beneficial in giving the condensables equal detectability, because (1) less material need be vaporized to achieve the same peak gas density in the ionizer, and (2) the ratio of reflected to nonreflected species is greatly reduced.

\section{SUMMARY}

Mass spectrometric analyses via dynamic sampling, particularly of high-temperature vapors, can lead to serious errors if some important factors are overlooked. These errors tend to emerge as discrimination against condensable and short-lived species. We have found that the mass spectrometer itself may cause little discrimination, but the manner in which vapors are introduced into it is extremely important. Nevertheless, dynamic sampling can be a reliable process if adequate precautions are taken at the inlet and, where possible, if the data acquisition devices are controlled at the output. These include locating the vapor source (or inlet) as close to the ionizer as possible and employing collimating slits and differential pumping to form a vapor beam that can be chopped (if not already pulsed) in synchronism with time-windows in the data acquisition instrumentation.

\section{REFERENCES}

1 G. Wells, J. H. Futrell and K. J. Voorhees, Rev. Sci. Instrum., 52 (1981) 735-740.

2 M. G. Inghram and J. Drowart, Proceedings of an International Symposium on High Temperature Technology, McGraw-Hill, New York, 1960, pp. 219-240.

3 T. A. Milne and M. N. Soltys, J. Anal. Appl. Pyrol., 5 (1983) 93-110.

4 K. A. Lincoln, Dynamic Mass Spectrometry, in D. Price and J. F. J. Todd (Eds.), Dynamic Mass Spectrometry, Vol. 6, Heyden \& Son, London, 1981, pp. 111-119.

5 M. A. Covington, G. N. Liu and K. A. Lincoln, AIAA J., 15 (1977) 11741179.

6 D. Price and S. Vaudrey, J. Phys. E: Sci. Instrom, 6 (1973) 67-70.

7 R. B. Van Breeman, M. Snow and R. J. Cotter, Int. J. Mass Spectrom. Ion Phys., 49 (1983) 35-50.

8 K. A. Lincoln, Int. J. Mass Spectrom. Ion Phys., 2 (1969) 75-83. 


\begin{tabular}{|c|c|c|c|}
\hline $\begin{array}{l}\text { 1. Report No. } \\
\text { NASA TM-85886 }\end{array}$ & 2. Government Accession No. & \multicolumn{2}{|c|}{ 3. Recipient's Catalog No. } \\
\hline \multirow{2}{*}{\multicolumn{2}{|c|}{$\begin{array}{l}\text { 4. Title and Subtitle } \\
\text { TECHNIQUES FOR AVOIDING DISCRIMINATION } \\
\text { ERRORS IN THE DYNAMIC SAMPLING OF } \\
\text { CONDENSABLE VAPORS }\end{array}$}} & \multicolumn{2}{|c|}{$\begin{array}{l}\text { 5. Report Date } \\
\text { December } 1983\end{array}$} \\
\hline & & \multicolumn{2}{|c|}{$\begin{array}{l}\text { 6. Performing Organization Code } \\
\text { ATP }\end{array}$} \\
\hline $\begin{array}{l}\text { 7. Author(s) } \\
\text { Kenneth A. Lincoln }\end{array}$ & & \multicolumn{2}{|c|}{$\begin{array}{l}\text { 8. Performing Organization Report No. } \\
\text { A-9511 }\end{array}$} \\
\hline \multirow{2}{*}{\multicolumn{2}{|c|}{$\begin{array}{l}\text { 9. Performing Organization Name and Address } \\
\text { Ames Research Center } \\
\text { Moffett Field, CA } 94035\end{array}$}} & \multicolumn{2}{|c|}{$\begin{array}{l}\text { 10. Work Unit No. } \\
\text { T-4204 }\end{array}$} \\
\hline & & \multicolumn{2}{|c|}{ 11. Contract or Grant No. } \\
\hline & & \multirow{2}{*}{\multicolumn{2}{|c|}{$\begin{array}{l}\text { 13. Type of Report and Period Covered } \\
\text { Technical Memorandum }\end{array}$}} \\
\hline \multirow{2}{*}{\multicolumn{2}{|c|}{$\begin{array}{l}\text { 12. Sponsoring Agency Name and Address } \\
\text { National Aeronautics and Space Administration } \\
\text { Washington, DC } 20546\end{array}$}} & & \\
\hline & & \multicolumn{2}{|c|}{$\begin{array}{l}\text { 14. Sponsoring Agency Code } \\
506-53-31-05-00-21\end{array}$} \\
\hline \multicolumn{4}{|c|}{$\begin{array}{l}\text { 15. Supplementary Notes } \\
\text { Point of Contact: K. A. Lincoln, Ames Researcl }\end{array}$} \\
\hline \multicolumn{4}{|c|}{$\begin{array}{l}\text { 16. Abstract } \\
\text { In the mass spectrometric sampling of dynamic systems, measurements of the relative } \\
\text { concentrations of condensable and noncondensable vapors can be significantly distorted if } \\
\text { some subtle, but important, instrumental factors are overlooked. Even with in situ measure- } \\
\text { ments, the condensables are readily lost to the container walls, and the noncondensables can } \\
\text { persist within the vacuum chamber and yield a disproportionately high output signal. Where } \\
\text { single pulses of vapor are sampled this source of error has been avoided by gating either the } \\
\text { mass spectrometer "on" or the data acquisition instrumentation "on" only during the very } \\
\text { brief time-window when the initial vapor cloud emanating directly from the vapor source } \\
\text { passes through the ionizer. Instrumentation for these techniques is detailed and its effective- } \\
\text { ness is demonstrated by comparing gated and nongated spectra obtained from the pulsed-laser } \\
\text { vaporization of several materials. }\end{array}$} \\
\hline $\begin{array}{l}\text { 17. Key Words (Suggested by Author (s)) } \\
\text { Mass spectrometry } \\
\text { Vaporization } \\
\text { Sampling of vapors }\end{array}$ & $\begin{array}{r}\text { 18. Distrib } \\
\text { Unli }\end{array}$ & ct category: 3 & \\
\hline $\begin{array}{l}\text { 19. Security Classif. (of this report) } \\
\text { Unclassified }\end{array}$ & $\begin{array}{l}\text { 20. Security Classif. (of this page) } \\
\text { Unclassified }\end{array}$ & $\begin{array}{c}\text { 21. No. of Pages } \\
10 \\
\end{array}$ & $\begin{array}{r}\text { 22. Price" } \\
\mathrm{AO} 2 \\
\end{array}$ \\
\hline
\end{tabular}

"For sale by the National Technical Information Service, Springfield, Virginia 22161 
